\title{
Editorial
}

\section{Millennial Musings}

$\mathbf{M}$ y day job calls for the management of many projects. For annual events, such as a postgraduate course, the year is often tacked on to the course name. Until now, this has never been a big deal. But every time I add the number "2000" to the name of a project, it sounds momentous!

In fact, the turn of the millennium is momentous, and editing this journal gives me a nice perch to watch it turn. The Journal of Clinical Psychiatry is a forum to archive and transmit new knowledge in clinical psychiatry. Never in my professional career has the pace of this progress been so vigorous and consistent. Science is reshaping our field—almost daily—in dramatic ways!

One way is in the development of new pharmaceutical products to alleviate the suffering of psychiatric patients. Although not every new drug is a great leap forward, these developments have largely been a boon. Nonpharmaceutical treatments also are being studied, such as repeated transcranial magnetic stimulation, which may one day be a substitute for electroconvulsive therapy. Neuroimaging technology continues to improve as well and promises someday to clarify heterogeneous syndromes into homogeneous diseases.

Before long, basic science research will inform clinical therapeutics. For example, we will know which receptors are involved with the disorder we seek to treat, and a drug will be formulated that can increase serotonin neurotransmission only at those receptors. Or, we will have means to break apart phenomenologically similar syndromes (e.g., different forms of depression) into biological subsets that need differing treatments (e.g., a norepinephrine "boost" rather than a serotonergic enhancement).

Perhaps in the future, drugs, which enter every cell in the body, will become obsolete and be replaced by focused treatments (energy beams?) that will go only to the site of the problem. In psychiatry, one can imagine adjusting aberrant brain centers that regulate mood, for example. And we may even envision a time when genetic engineering will correct nucleic acid sequences for people who react to stress by losing touch with reality.

But these treatments will only work if patients have access to them. As we near the opening of a new century, no one can foretell what will become of the health care system in the United States. I believe our current system of managed care, with huge profits for a few and a gutting of care for many, is entering its last phase. Some foresee a single-payer system. I lean toward locally or regionally based systems, with partnerships between governments and not-for-profit institutions. Being near the end of their growth phase, investor-owned companies are likely to exit the scene in the near future, leaving the rest of us to pick up the pieces and take care of the sick.

Recent years have seen growing alliances between professional and scientific constituencies and advocacy groups. At times there are differences of opinions, but by and large the patients we treat and their family members have the strongest voices to influence legislators, executives, and regulators. As research opens new doors for enhanced treatment, advocacy can lead to much-needed reforms, such as parity of health insurance coverage to enable optimum treatment of mental illnesses. Calling recently for "equitable coverage for mental illness," The New York Times stated: "The brain is an organ, and diseases related to this organ should be treated like any other medical illness." (The New York Times editorial, Thursday, June 10, 1999).

I continue to be impressed by the passion, commitment, and altruism of so many people in our professional community and its "neighborhood": basic and clinical scientists, practitioners, and advocates for the mentally ill. The Journal of Clinical Psychiatry will continue to help you keep abreast of the rapid developments in our field—-today and well into the future. 